\title{
Audit Tata Kelola Teknologi Informasi dengan Framework Cobit 5 di PT. Best Stamp Indonesia
}

\author{
Zen Munawar, S.T, S.Kom., M.Kom \\ Dosen Tetap Prodi Manajemen Informatika \\ Politeknik LP3I Bandung \\ E-mail:munawarzen@gmail.com
}

\begin{abstract}
Abstrak : Pemakaian Teknologi Informasi pada PT. Best Stamp Indonesia saat ini telah dilakukan audit dengan COBIT 4.1 namun seiring perkembangan COBIT maka perlu diketahui jika dilakukan dengan COBIT 5 bagaimana efisiensi dan process capability levels tata kelola teknologi informasi yang sudah ada. Audit tata kelola teknologi informasi dimaksudkan untuk membuat pemetaan proses monitoring, evaluasi dan akses terhadap process capability levels.
\end{abstract}

Berdasarkan hal tersebut maka perlu dilakukan audit dengan COBIT 5 dalam pengelolaan teknologi informasi, agar dapat mengetahui sejauh mana penerapan tata kelola Teknologi Informasi dan apakah sistem yang telah dibuat sesuai tujuan perusahaan. Dalam penelitian ini menggunakan model process capability levels sebagai alat ukur terhadap jawaban responden dari kuesioner yang dibuat berdasarkan framework Cobit 5 serta sebagai definisi dan pemahaman proses tata kelola teknologi informasi yang sedang berjalan. Dari rekapitulasi jawaban dari para responden, maka didapatkan nilai process capability levels saat ini sebesar 3,0 pada skala $0-5$.

Agar bisa mendapatkan hasil yang diharapkan, maka dibuatlah beberapa usulan untuk meningkatkan kinerja serta sebagai acuan perbaikan tata kelola teknologi informasi di PT. Best Stamp Indonesia dimasa yang akan datang. Dari hasil implementasi diperoleh hasil bahwa model tata kelola TI dan model audit sistem informasi COBIT dapat diterapkan pada proses teknologi informasi di perusahaan, namun demikian perlu dilakukan penyesuain atau modifikasi terhadap prosesnya.

Kata Kunci : Audit, Tata Kelola Teknologi Informasi, Cobit 5, process capability levels

\section{Pendahuluan}

Di era globalisasi saat ini penggunaan Teknologi Informasi (TI) telah menjadi suatu kebutuhan yang memegang peranan penting dalam berbagai aspek kehidupan. TI pun telah memberikan banyak manfaat bagi perkembangan proses bisnis. "Effective strategy development is becoming vital for today's Organizations. As the impact of IT has grown in organizations, IT strategy is finally getting the attention it deserves in business". (Heather, James, and Satyendra, 2007). Perusahaan semakin berusaha menjadi yang terbaik, demikian pula halnya dengan PT. Best Stamp Indonesia berusaha menerapkan strategi terbaik dalam menggunakan TI mereka. 
Menurut pernyataan A. Gunasekaran et al, 2001 "To remain competitive and ever increasingly sophisticated in the marketplace, businesses must invest in Information Technology (IT) if they are to survive in the long-term. Advances in IT have enabled new competitors to enter existing markets more readily, which has stimulated and strengthened the paradigm of global competitiveness". Pemanfaatan TI telah memberikan solusi dan keuntungan melalui peluangpeluang sebagai bentuk dari peran strategis TI dalam pencapaian visi dan misi organisasi.

TI menjadi tulang punggung dan elemen penting organisasi untuk dapat bertahan dan mempunyai kesempatan dalam meraih keunggulan kompetitif. Perusahaan menjadi lebih bertahan dan lebih unggul dibanding perusahaan sejenis bila dapat memanfaatkan investasi TI-nya dengan baik.

Stacey Hamaker, CISA, dan Austin Hutton, 2004, mengemukakan bahwa "IT governance is an integral part of corporate governance in raising the bar of corporate integrity and enhancing shareholder value. IT governance goes beyond IT audit and beyond what the CIO can accomplish by himself/herself. Depending on the organization, IT governance may be the enabler for an organization to move to the next level or it may be the only way an organization can meet regulatory and legal requirements".

Peluang-peluang diciptakan dari optimalisasi sumber daya TI pada area sumber daya organisasi yang meliputi data, sistem aplikasi, infrastruktur dan sumber daya manusia.

Disisi lain penerapan TI memerlukan biaya investasi yang relatif mahal. Dimana munculnya resiko terjadinya kegagalan yang cukup besar. Kondisi ini memerlukan konsistensi dalam bidang pengelolaan sehingga suatu Tata Kelola TI (TI Governance) yang baik dan sesuai akan menjadi kebutuhan yang esensial. Tata kelola TI yang baik adalah yang mampu membuat perusahaan bertahan dan membantu mengembangkan strategi dan mewujudkan tujuan dari perusahaan.

PT. Best Stamp Indonesia melakukan Tata kelola TI pengawasan dan evaluasi oleh bagian penunjang sistem (system support department) membawahi kepala penunjang sistem (head system support) yang terdiri dari seksi auditor, seksi analyst audit data staff, seksi web system of sales report staff, seksi IT support, seksi checker, seksi web system of logistics staff dan seksi logistics staff.

Kerangka kerja COBIT 5 membagi menjadi dua area, yaitu governance dan management. Jumlah dari kedua area adalah 5 domain dan 37 proses sebagai berikut. Area 1, Governance of Enterprise IT dengan Domain Evaluate, Direct and Monitor (EDM) sebanyak 5 proses. Area 2, Management of Enterprise IT dengan Domain Align, Plan and Organize (APO) sebanuyak 13 proses, Domain Builds, Acquire and Implement (BAI) sebanyak 10 proses, Domain Deliver, Service and Support (DSS) sebanyak 6 proses, dan terakhir Domain Monitor, Evaluate and Assess (MEA) sebanyak 3 proses. 
Domain yang digunakan dari kerangka kerja COBIT 5 untuk melakukan audit tata kelola TI di PT. Best Stamp Indonesia adalah Domain Monitor, Evaluate and Assess (MEA), dikarenakan pada tata kelola TI di perusahaan tersebut sudah berjalan, maka evaluasi dilakukan pada tata kelola yag ada.

Adapun Identifikasi masalahnya sebagai berikut. Berapa process capability levels tata kelola Teknologi informasi di PT. Best Stamp Indonesia jika diukur dengan menggunakan kerangka kerja COBIT 5 ?

Ruang lingkup penelitian dalam hal ini yaitu melakukan audit dengan cara menganalisis penerapan tata kelola TI. Dalam penelitian yang akan dikaji hanya Domain MEA saja . Lingkup tata kelola TI yang di kaji process capability levels tatakelola TI dengan COBIT 5 di PT. Best Stamp Indonesia.

Penelitian ini bertujuan mengaudit tata kelola teknologi informasi guna mengetahui sejauh mana process capability levels tata kelola teknologi informasi di PT. Best Stamp Indonesia. Sedangkan manfaat dari audit ini adalah dapat mengetahui apakah sistem yang telah dibuat sudah sesuai dengan rencana Strategis yang ada, dan mengetahui tingkat kematanga tata kelola teknologi informasi dengan menggunakan COBIT 5.

Metodologi penelitian dilakukan dengan cara penetapan dan penyesuaian definisi pada kerangka kerja COBIT 5, terutama pada area tata-kelola (governance) di domain Pengawasan, Evaluasi, dan Akses (Monitor, Evaluate, and Assess/MEA), agar sesuai dengan tata-kelola yang akan diberlakukan di Perusahaan.

Penelitian menggunakan cara observasi dan melakukan analisis statistik untuk menyatakan kondisi awal, untuk kemudian melakukan implementasi dari langkahlangkah kerja yang diperlukan sesuai kerangka kerja COBIT 5 agar dapat meningkatkan tata kelola teknologi informasi serta mendefinisikan rekomendasi yang bisa dilakukan selanjutnya oleh perusahaan di masa yang akan datang.

\section{Tinjauan Pustaka}

\subsection{Tata Kelola Perusahaan}

Institute for Enterprise Architecture Developments (2009) mengemukakan tentang tata kelola perusahaan adalah sebuah struktur dan hubungan yang mengontrol, mengarahkan, atau mengatur kinerja dari proyek, portofolio, infrastruktur, serta proses bisnis sebuah perusahaan. Tata kelola perusahaan ini akan diturunkan menjadi tata kelola teknologi informasi yang difokuskan pada pengaturan penggunaan teknologi informasi pada perusahaan saat ini.

Menurut International Federation of Accountant (2004) tata kelola adalah kumpulan dari cara dan aturan untuk menjalankan sebuah prosedur serta standart operasional dalam mencapai suatu tujuan strategis. Tata kelola perusahaan (enterprise governance) dapat diartikan sebagai sebuah set tanggung jawab dan praktek kerja yang dilakukan oleh dewan serta eksekutif manajamen yang 
bertujuan untuk menyediakan arahan strategis, untuk memastikan agar tercapainya sasaran perusahaan, mengendalikan segala risiko yang mungkin terjadi sehingga memastikan agar sumber daya perusahaan digunakan dengan sesuai. Dengan adanya tata kelola perusahaan yang baik diharapkan tingkat kepercayaan serta perlindungan investasi lebih terjamin.

\subsection{Tata Kelola Teknologi Informasi}

Terdapat beberapa definisi mengenai IT governance diantaranya adalah: Pengertian IT governance menurut ITGI (2007: 5) :

IT governance is the responsibility of executives and the board of directors, and consists of the leadership, organisational structures and processes that ensure that the enterprise's IT sustains and extends the organisation's strategies and objectives.

Berdasarkan definisi tersebut bahwa IT governance merupakan tanggung jawab dari pimpinan puncak dan eksekutif manajemen dari suatu perusahaan. Dapat dijelaskan pula bahwa IT governance merupakan bagian dari pengelolaan perusahaan secara keseluruhan yang terdiri dari kepemimpinan dan struktur organisasi dan proses yang ada adalah untuk memastikan kelanjutan TI organisasi dan pengembangan strategi dan tujuan dari organisasi.

Menurut Grembergen, Haes (2004:1). IT governance adalah:

IT governance is the organizational capacity excercised by the Board, excecutive management and IT management to control the formulation and implementation of IT strategy and in this way ensure the fusion of business and IT

Dari pengertian tersebut tata kelola teknologi informasi merupakan tindakan organizasional yang dilakukan oleh dewan, manajemen eksekutif dan juga manajemen TI untuk mengendalikan formulasi dan implementasi dari strategi TI dan caranya untuk meyakini bisnis dan $\mathrm{Tl}$ itu sendiri.

Peluang-peluang diciptakan dari optimalisasi sumber daya TI pada area sumber daya organisasi yang meliputi data, sistem aplikasi, infrastruktur dan sumber daya manusia. Seperti diungkapkan oleh Stacey Hamaker, CISA, dan Austin Hutton, 2004, bahwa

"IT governance is an integral part of corporate governance in raising the bar of corporate integrity and enhancing shareholder value. IT governance goes beyond IT audit and beyond what the CIO can accomplish by himself/herself. Depending on the organization, IT governance may be the enabler for an organization to move to the next level or it may be the only way an organization can meet regulatory and legal requirements".

Berdasarkan definisi-definisi tersebut di atas dapat dilihat bahwa penekanan dari IT governance adalah pada terciptanya keselarasan yang strategis antara Teknologi Informasi dengan bisnis dari suatu perusahaan dan pihak manajemen 
juga mempunyai peranan yang sangat penting dalam penerapan tata kelola teknologi informasi.

\subsection{COBIT 5 Framework}

Control Objective for Information and Related Technologi (COBIT) merupakan suatu framework yang dikembangkan oleh IT Governance Institute (ITGI) yang merupakan bagian dari Information Systems Audit and Control Association (ISACA), ITGI adalah sebuah organisasi yang melakukan studi tentang model pengelolaan TI yang berbasis di Amerika Serikat.

COBIT memberikan kebijakan yang jelas dan praktik yang baik dalam tata kelola teknologi informasi dengan membantu manajemen senior dalam memahami dan mengelola risiko yang terkait dengan tata kelola teknologi informasi dengan cara memberikan kerangka kerja tata kelola teknologi informasi dan panduan tujuan pengendalian terinci / detailed control objective bagi pihak manajemen, pemilik proses bisnis, pengguna dan juga auditor.

COBIT mengalami evolusi yang cukup panjang dan semakin baik sebagai framework yang bisa digunakan dalam menerapkan Governance of Enterprise IT (Van Grembergen, 2009).

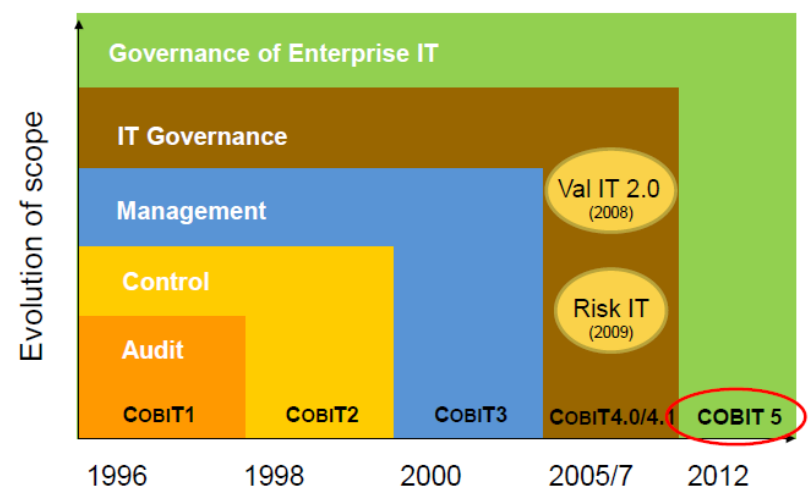

Gambar 2.1. Sejarah Kerangka Kerja Bisnis berdasarkan ISACA (Sumber ITGI, 2012)

COBIT 5 menurut ISACA adalah sebuah kerangka kerja untuk tata kelola dan manajemen teknologi informasi dan semua yang berhubungan, yang dimulai dari memenuhi kebutuhan stakeholder akan informasi dan teknologi.

COBIT 4.1 dengan COBIT 5 mempunyai beberapa perbedaan, terutama dalam pembagian domain dan aktivitas proses kerjanya. Pada kerangka kerja COBIT 5, terdapat pemisahaan yang tegas antara tata-kelola dengan manajemen (ITGI, 2012). Tata kelola pada sebagian besar perusahaan merupakan tanggung jawab dari dewan direksi yang dipimpin oleh pemilik, sedangkan pengaturan merupakan tanggung jawab semua manajer eksekutif yang dipimpin oleh direktur operasional dalam menjalankan operasional kerja. 
Pada COBIT 5 terbagi menjadi 2 area, yaitu governance dan management. Total dari kedua area terdiri dari 5 domain dan 37 proses sebagai berikut :

Area 1, Governance of Enterprise IT

a. Evaluate, Direct and Monitor (EDM) -5 proses

Area 2, Management of Enterprise IT

a. Align, Plan and Organize (APO) - 13 Proses

b. Build, Acquire and Implement (BAI) -10 proses

c. Deliver, Service and Support (DSS) -6 proses

d. Monitor, Evaluate and Assess (MEA) - 3 proses

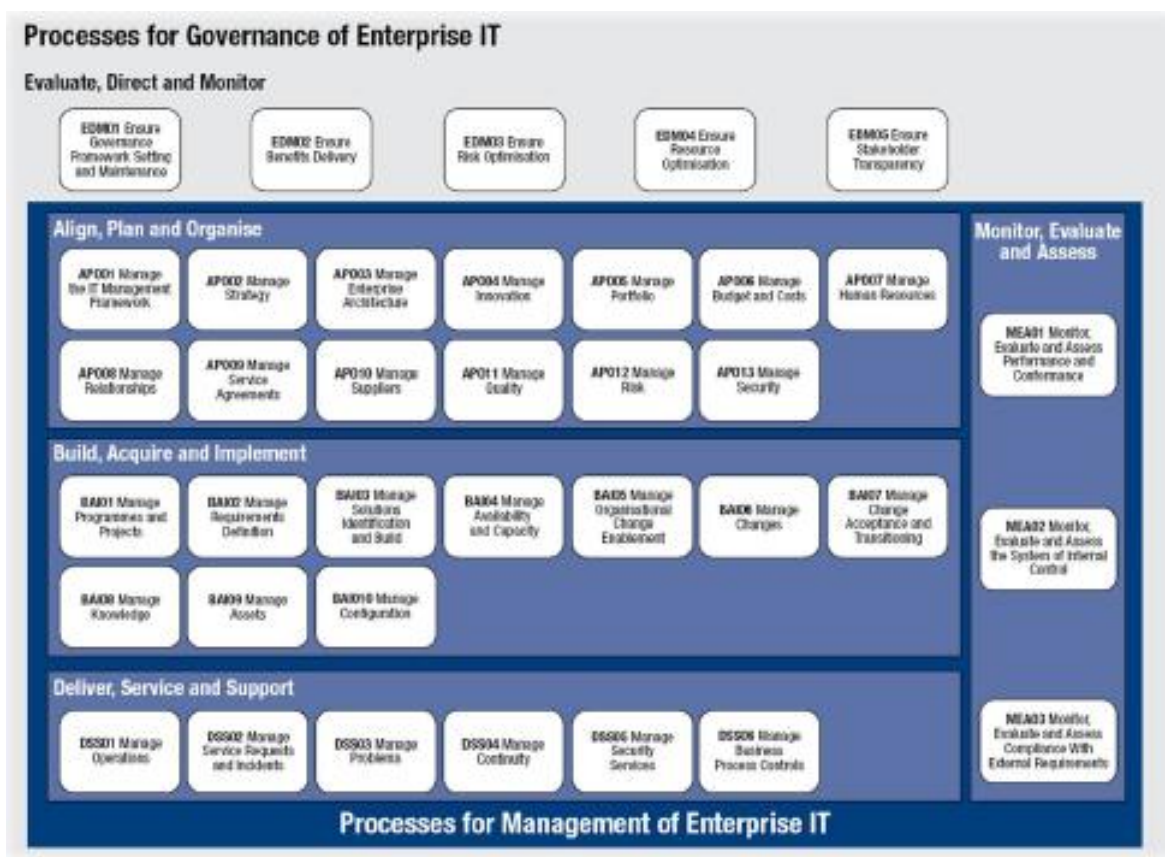

Gambar 2.2. COBIT 5 Process Reference Model

(Sumber ITGI, 2012)

Dari COBIT 5 ini diambil domain MEA (Monitor, Evaluate and Asses).

\section{Hasil Penelitian dan Pembahasan}

\subsection{Hasil Penelitian}

Dalam penelitian ini menggunakan maturity model sebagai alat ukur terhadap jawaban responden dari kuesioner yang dibuat berdasarkan framework cobit 5 . Kuesioner ini berisi tentang pertanyaan-pertanyaan dari domain Monitor, Evaluate, and Access (MEA), yaitu:

\section{Monitor, Evaluate, and Access (MEA01)}

Pengawasan, evaluasi penilaian kinerja proses teknologi informasi pada PT. Best Stamp Indonesia terhadap kebijakan yang telah ditetapkan dan memberikan laporan yang sistematis dan tepat waktu kepada Direktur.

2. Monitor, Evaluate, and Access (MEA02) 
Pengawasan, evaluasi dan penilaian sistem pengendalian internal, termasuk dalam merencanakan, mengatur dan menjaga standarisasi untuk penilaian pengendalian internal dan jaminan proses kegiatan, dalam dalam hal ini menyediakan program pelatihan mengenai pemanfaatan teknologi informasi dan komunikasi kepada pengguna sistem.

3 Monitor, Evaluate, and Access (MEA03)

Pengawasan, evaluasi dan penilaian sistem pengendalian ekternal yaitu mengidentifikasi dan memonitor perubahan dalam kebijakan, peraturan dan ketetapan lainnya yang harus dipenuhi dari teknologi informasi secara terus menerus. Pada PT. Best Stamp Indonesia, evaluasi dan revisi mengenai kebijakan-kebijakan ini dilakukan secara rutin setiap setahun sekali.

Tabel 3.1. Process capability levels Proses Teknologi Informasi

\begin{tabular}{|c|c|c|c|c|}
\hline Domain & Proses & $\begin{array}{l}\text { Rata-rata } \\
\text { Responden }\end{array}$ & $\begin{array}{l}\text { Rata-rata } \\
\text { Sub Proses }\end{array}$ & $\begin{array}{c}\text { Rata-rata } \\
\text { Proses }\end{array}$ \\
\hline \multirow{6}{*}{ MEA01 } & MEA01.01 & 3,02 & \multirow{6}{*}{18,25} & \multirow{6}{*}{3,04} \\
\hline & MEA01.02 & 3,05 & & \\
\hline & MEA01.03 & 3,12 & & \\
\hline & MEA01.04 & 2,98 & & \\
\hline & MEA01.05 & 3,00 & & \\
\hline & MEA01.06 & 3,08 & & \\
\hline \multirow{6}{*}{ MEA02 } & MEA02.01 & 3,07 & \multirow{6}{*}{18,30} & \multirow{6}{*}{3,05} \\
\hline & MEA02.02 & 3,03 & & \\
\hline & MEA02.03 & 3,00 & & \\
\hline & MEA02.04 & 3,15 & & \\
\hline & MEA02.05 & 2,97 & & \\
\hline & MEA02.06 & 3,08 & & \\
\hline \multirow{6}{*}{ MEA02 } & MEA02.01 & 2,95 & \multirow{6}{*}{18,60} & \multirow{6}{*}{3,10} \\
\hline & MEA02.02 & 3,20 & & \\
\hline & MEA02.03 & 3,07 & & \\
\hline & MEA02.04 & 3,17 & & \\
\hline & MEA02.05 & 3,02 & & \\
\hline & MEA02.06 & 3,20 & & \\
\hline \multicolumn{3}{|c|}{$\mathrm{Jumlah}$} & 55,15 & \multirow{3}{*}{$\begin{array}{l}9,19 \\
3,06\end{array}$} \\
\hline & ata-rata Sub F & & 3,06 & \\
\hline \multicolumn{4}{|c|}{ Process capability levels } & \\
\hline
\end{tabular}

Dari tabel di atas, diperoleh nilai process capability levels saat ini sebesar 3,06 pada rentang 0-5. Nilai tertinggi terdapat pada MEAO3 yaitu sebesar 3,10, sedangkan nilai terendah terdapat pada $M E A 01$ sebesar 3,04.

\subsection{Pembahasan}

Berdasarkan dari data yang diperoleh dari kuisioner selanjutnya diolah dan dilakukan langkah-langkah sebagai berikut ini :

1. Dihitung rata-rata terhadap masing-masing jawaban dari semua responden. 
2. Dilakukan penilaian tingkat model kematangan proses tersebut diperoleh dengan melakukan perhitungan rata-rata semua proses.

3. Didapat kondisi Teknologi Informasi yang ada.

Untuk memudahkan hasil penelitian dibuat dalam bentuk Indeks dengan model kematangan sebagai berikut : Indeks $=\sum$ Jawaban Kuesioner $/ \sum$ Pertanyaan Kuesioner.

Indeks $=\left(\sum\right.$ MEA01 $+\sum$ MEA02 $+\sum$ MEA03 $) / \sum$ Domain Proses

Indeks $=(3,04+3,05+3,10) / 3$

Indeks $=3,06$

Adapun skala Pembulatan Indeks terdapat pada tabel berikut :

Tabel 3.2. Skala Pembulatan Indeks.

\begin{tabular}{|c|c|}
\hline Level & Maturity Model \\
\hline 0 & Incomplette Process \\
\hline 1 & Performed Process \\
\hline 2 & Managed Process \\
\hline 3 & Established Process \\
\hline 4 & Predictable Process \\
\hline 5 & Optimising Process \\
\hline
\end{tabular}

Hasil pengukuran Process capability levels dapat dilihat pada tabel

Tabel 3.3. Hasil Pengukuran Process capability levels Proses Teknologi Informasi

\begin{tabular}{|c|c|c|}
\hline Kontrol Proses TI & $\begin{array}{c}\text { Kondisi saat ini } \\
\text { Rata-rata PerProses }\end{array}$ & $\begin{array}{c}\text { Tingkat Model } \\
\text { Kematangan }\end{array}$ \\
\hline MEA01 & 3,04 & Established Process \\
\hline MEA01 & 3,05 & Established Process \\
\hline MEA01 & 3,10 & Established Process \\
\hline $\begin{array}{c}\text { Total Nilai Process capability } \\
\text { levels }\end{array}$ & 3,06 & Established Process \\
\hline
\end{tabular}

Dari tingkat model kematangan skala penerapan dengan kerangka kerja COBIT 5 pada tata kelola teknologi informasi di PT. Best Stamp Indonesia terdapat pada skala 3 dengan nilai 3,06. Hal ini berarti perusahaan telah mengimplementasikan tata kelola teknologi informasi yang sesuai dengan rencana strategis dan sesuai dengan target yang ditetapkan.

\section{Kesimpulan}

Dari hasil audit yang telah dilakukan, diperoleh kesimpulan rekapitulasi process capability levels tata kelola teknologi informasi pada PT. Best Stamp Indonesia adalah established process dan terdapat pada skala 3 dengan nilai 3,06. Dengan demikian PT. Best Stamp Indonesia telah mengimplementasikan tata kelola teknologi informasi. Namun demikian diharapkan dimasa yang akan datang dapat ditingkatkan. 


\section{Daftar Pustaka}

[1] Alberch, Bob \& Pirani, Judith A.2004. Using an IT Governance Structure to Archieve Alignment at the University of Cincinnati.

[2] Board Briefing IT Governance $2^{\text {nd }}$ edition, ITGI, 2007

[3] COBIT 5.0 http://www.isaca.com/cobit-5-guideline

[4] Grembergen, Wim Van and Steven De Haes. 2009. Enterprise Governance of IT: Achieving Strategic Alignment and Value, Springer

[5] Grembergen, Wim Van and Steven De Haes, IT Governance and Its Mechanisms, Information Systems Audit and Control Association, 2004

[6] Grembergen, Wim Van (2004), Strategien For Information Technology Governance, Idea Group Publishing, Idea Group Publishing, 2004

[7] Grembergen, Wim Van, Steven De Haes \& Eric Guldentops, Structures, Processes and Relational Mechanisms for IT Governance, Idea Group Publishing, 2004

[8] ISACA, COBIT 5 : Enabling Process, ITGI. 2012, United States America.

[9] ISACA, COBIT 5, ITGI, 2012

[10] ISACA, COBIT 5 Implementation, ITGI, 2012

[11] Stacey Hamaker, CISA, and Austin Hutton, Principles-of-IT-Governance, Information Systems Control Journal, Volume 2. 2004 